\title{
Analysis on the Barriers and Countermeasures of Chinese Medicine Enterprises for Countries along the Belt and Road
}

\author{
Wannan Wang \\ International Business School \\ Yunnan University of Finance and Economics \\ Kunming, China \\ 343601383@qq.com \\ Yongsong Liu* \\ School of Communication \\ Yunnan University of Finance and Economics
}

\author{
Yunnan, China \\ 793350453@qq.com \\ Yunlong Duan \\ International Business School \\ Yunnan University of Finance and Economics \\ Kunming, China \\ 827987867@qq.com
}

\begin{abstract}
Culture is the bridge connecting countries in the construction of The Belt and Road Initiative. Chinese medicine, one of the essences of traditional Chinese culture, not only shoulders the responsibility of such bridges and bonds, but also faces an excellent opportunity to go with the The Belt and Road counterparts to the world. The Chinese medicine industry is a traditional industry with comparative advantages in China. However, for a long time, the share of traditional Chinese medicine exports in the international market has been very low. This article first analyzes the status of Chinese medicine exports, which can analyze the problems existing in the export of Chinese medicine, and finally from the government and the enterprise level to propose countermeasures against the barriers.
\end{abstract}

Keywords-The Belt and Road; Chinese medicine companies; technical barriers

\section{INTRODUCTION}

Since the 18th National Congress of the Communist Party of China, the party and government have placed the development of Chinese medicine in a more important position and made a series of major decisions. At the National Health and Health Conference, General Secretary Xi Jinping stressed that it is necessary to "strive to promote the development of Chinese medicine." The Eighteenth National Congress of the Communist Party of China and the Fifth Plenary Session of the 18th CPC Central Committee put forward the principle of "adhering to equal emphasis on Chinese and Western medicine" and "supporting the development of Chinese medicine and ethnic medicine".

The important strategic concept of the "Building the Silk Road Economic Belt" and the "21st Maritime Silk Road Economic Belt" proposed by the Third Plenary Session of the 18th CPC Central Committee have brought new historical opportunities for the development of the Chinese medicine international market. On December 26, 2016, the National
Development and Reform Commission of the State Administration of Traditional Chinese Medicine printed and issued the "One Belt and One Road One Road" Development Plan for Chinese Medicine (2016-2020). The plan sets out its development goals: By 2020, the new pattern of all-round cooperation in the "Belt and Road" initiative of TCM will basically take shape. The domestic policy support system and international coordination mechanism will be gradually improved. Based on neighboring countries and key countries, 30 overseas centers for Chinese medicine will be established in cooperation with countries along the route. Twenty TCM international standards have been promulgated, 100 kinds of TCM products have been registered, and 50 TCM external communication and cooperation demonstration bases have been built. The value of TCM medical and health care is widely recognized by the public along the route. More countries along the route recognize the legal status of TCM, and Chinese TCM cooperates with them to achieve greater scope, higher level, and deeper levels of openness, exchanges, and integration [1]

With the launch of the "Chinese Medicine" white paper and development plans and other Chinese medicine policy documents, the implementation of Chinese medicine exchange cooperation with countries along the "Belt and Road" initiative, and the strengthening of cooperation with the WHO, the development strategy of Chinese medicine It has risen to a national strategy, and Chinese medicine "going to the world" is ushering in the best period of development.

With the expansion of world trade, Chinese medicine has gradually entered the international market as a trade commodity. Large-scale Chinese medicine companies have emerged continuously. Traditional Chinese medicine companies such as the Yunnan Baiyao Group are using their modern technology and unique herbal advantages to actively develop the international market for Chinese medicine. However, entering the international market as a drug and

*Corresponding author 
being recognized is still very difficult. The international market share is not commensurate with the status of China's Chinese herbal medicine production. On the contrary, Japan, South Korea, the United States and other countries use China's raw materials for $\mathrm{R} \& \mathrm{D}$, accounting for $80 \%$ of the international market share. In this case, of course, domestic companies have their own reasons. At the same time, the protectionism in the international market and the differences in the Eastern and Western cultures also play a considerable role in the development of the international market. The status quo of the barriers to trade of traditional Chinese medicine exports has seriously affected the internationalization of Chinese medicine products in China [2].

\section{The StATUs QUO OF CHINESE Medicine EXPORTS IN CHINA}

China is rich in traditional Chinese medicine resources, including not only animal and plant medicines, but also mineral medicines. There are many kinds of Chinese medicines; the country's production area of traditional Chinese medicines is more than 3,496,933.33 hectares, with large reserves. In recent years, Chinese medicine has been more widely recognized internationally, the international market continues to expand, the situation of Chinese medicine exports is promising, and the export volume of Chinese medicines generally shows an upward trend year by year (as shown in Figure 1).

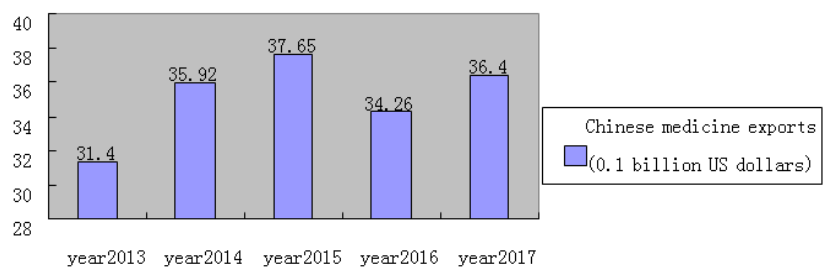

Fig. 1. China's exports of Chinese medicine from 2013 to 2017 (unit: USD 100 million)

\section{A. The Overall Scale of Chinese Medicine Exports}

China is the birthplace and resource-rich country of traditional Chinese medicine, and we can learn from the data on China's exports of Chinese medicine and total exports of China from 2013 to 2017 (as shown in Figure 1, Figure 2): The total export volume of Chinese medicine products is not large, and the proportion of China's export products is relatively low, which is about $0.16 \%$. At present, the annual sales volume of the proprietary Chinese medicine market in the world reaches more than 30 billion U.S. dollars, while China, which has the absolute advantage of resources in absolute Chinese herbal medicines, only accounts for $5 \%$ of the total. While the demand for international botanical drugs has grown rapidly, the market competition for TCM products has become increasingly fierce, and the share and effectiveness of Chinese TCM in the international market have been declining. The above phenomenon is extremely incompatible with the status of China's traditional Chinese medicine giant [3].

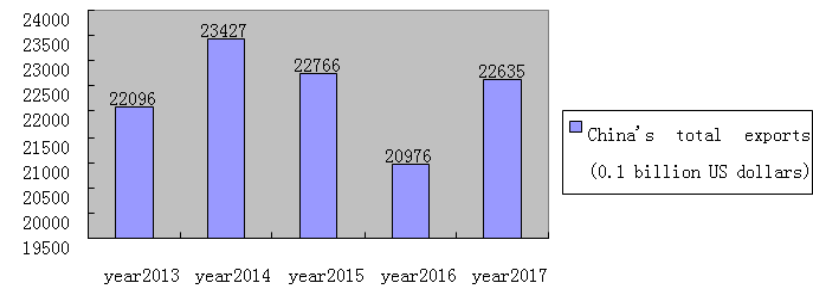

Fig. 2. China's total exports from 2013 to 2017 (unit: US\$100 million)

\section{B. China's Traditional Chinese Medicine Export Product Structure}

The forms of Chinese medicine exports are divided into: traditional Chinese medicines, plant extracts, Chinese herbal medicines and decoction pieces, and health products. (For the export situation in recent years, see Table I). In 2017, the export volume of Chinese medicines in China was 3.640 billion U.S. dollars, an increase of $2.07 \%$ year-on-year. The market for plant extracts was active with an export value of US\$2.01 billion, an increase of $4.33 \%$ over the same period last year. The exports of Chinese patent medicines were US\$250 million, an increase of $11.03 \%$ year-on-year. The export volume of Chinese herbal medicines and decoction pieces was 250 million U.S. dollars, continuing negative growth, which was a decrease of $2.23 \%$ year-on-year. According to statistical data, the export volume of Chinese herbal medicines and decoction pieces is the second largest export of Chinese medicinal products, and plant extracts are the largest category of Chinese herbal medicine exports. The share of Chinese patent medicines in the export of Chinese medicine products has been very low and has been declining year by year, and its growth rate has been slow

TABLE I. CHINA'S EXPORT STRUCTURE OF CHINESE MEDICINE, 2013-2017 (UNIT: 0.1 BILLION US DOLLARS, \%)

\begin{tabular}{|c|c|c|c|c|c|c|c|c|c|}
\hline Year & \multicolumn{2}{|c|}{$\begin{array}{c}\text { Chinese patent } \\
\text { medicine }\end{array}$} & \multicolumn{2}{|c|}{ Plant extracts } & \multicolumn{2}{c|}{$\begin{array}{c}\text { Chinese herbal } \\
\text { medicines and } \\
\text { decoction pieces }\end{array}$} & \multicolumn{2}{|c|}{ Health products } & $\begin{array}{c}\text { Total } \\
\text { export } \\
\text { amount }\end{array}$ \\
\cline { 2 - 10 } & $\begin{array}{c}\text { Export } \\
\text { amount }\end{array}$ & $\begin{array}{c}\text { Proportio } \\
\boldsymbol{n}\end{array}$ & $\begin{array}{c}\text { Export } \\
\text { amount }\end{array}$ & $\begin{array}{c}\text { Proportio } \\
\boldsymbol{n}\end{array}$ & $\begin{array}{c}\text { Export } \\
\text { amount }\end{array}$ & $\begin{array}{c}\text { Proportio } \\
\boldsymbol{n}\end{array}$ & $\begin{array}{c}\text { Export } \\
\text { amount }\end{array}$ & $\begin{array}{c}\text { Proportio } \\
\boldsymbol{n}\end{array}$ \\
\hline 2013 & 2.7 & 8.6 & 14.1 & 44.9 & 12.1 & 38.54 & 2.5 & 7.96 & 31.4 \\
\hline 2014 & 2.5 & 6.96 & 17.77 & 49.47 & 12.95 & 36.05 & 2.7 & 7.52 & 35.92 \\
\hline 2015 & 2.62 & 6.95 & 21.63 & 57.37 & 10.58 & 28.06 & 2.82 & 7.48 & 37.65 \\
\hline 2016 & 2.25 & 6.57 & 19.27 & 56.25 & 10.25 & 29.91 & 2.49 & 7.27 & 34.26 \\
\hline 2017 & 2.5 & 6.87 & 20.1 & 55.22 & 11.4 & 31.32 & 2.4 & 6.59 & 36.4 \\
\hline
\end{tabular}


Through the analysis of the Chinese export structure of Chinese traditional medicine from 2013 to 2017, we can conclude that Chinese herbal medicine exports are mainly low-value added Chinese herbal medicines and plant extracts. As the essence of traditional Chinese medicine and the relatively high value-added Chinese patent medicine exports have no advantage, the export of traditional Chinese medicine technology is low, the commodity structure and the origin of the origin of Chinese medicine does not match. According to the principle of pursuing profit maximization, Chinese medicine exports should break through the original framework, strengthen independent innovation capabilities and research and development capabilities, pay attention to the research and export of proprietary Chinese medicines, and participate in local competition. The pursuit of high added value is the main direction of Chinese medicine exports [4].

\section{China's Export Status of Traditional Chinese Medicine in the Belt and Road Initiative}

Since 2008, the total volume of import and export trade of Chinese medicines and countries and regions along the Belt and Road has been rising. In 2008, China's trade volume with the "Belt and Road" countries was 7.8 billion U.S. dollars, and this number climbed to 2.543 billion U.S. dollars in 2014, an increase of 2.26 times. By the end of 2017, 17 overseas centers for Chinese medicine were established in countries and regions along the "Belt and Road." Chinese medicine companies provide medical products and services that are inexpensive and effective for countries and regions along the "Belt and Road" initiative. This has, to a certain extent, broken the monopoly of Western pharmaceutical companies on the medical market.

1) China's exports of Chinese herbal medicines to the "Belt and Road" countries and regions increased significantly year-on-year

From January to November 2017, China's export of traditional Chinese medicine to the "Belt and Road" countries and regions amounted to US\$760 million, an increase of $12.05 \%$ over the same period of last year. Among them, the export value of Chinese herbal medicines was 260 million U.S dollars, an increase of $54.39 \%$ year-on-year, accounting for $34.35 \%$ of China's export volume of traditional Chinese medicines to the "Belt and Road" countries and regions. The major export destinations are ASEAN, South Asia and the Middle East (as shown in Table II).

TABLE II. EXPORT Status of Chinese Traditional MEdicine CORPORATION IN JANUARY-November 2017 (Unit: 10,000 US DOLLARs, \%)

\begin{tabular}{|c|c|c|c|c|c|c|}
\hline No. & Country & $\begin{array}{c}\text { Number of } \\
\text { exports }\end{array}$ & $\begin{array}{c}\text { Number of } \\
\text { exports compared } \\
\text { to the same } \\
\text { period }\end{array}$ & Export amount & $\begin{array}{l}\text { The export amount } \\
\text { is the same as the } \\
\text { previous year }\end{array}$ & $\begin{array}{c}\text { The proportion of } \\
\text { export amount }\end{array}$ \\
\hline 1 & Vietnam & 12062054 & 241.57 & 10021.59 & 394.40 & 38.35 \\
\hline 2 & Malaysia & 7719560 & -3.62 & 4167.68 & -5.29 & 15.95 \\
\hline 3 & India & 10941572 & 184.25 & 2097.37 & 160.45 & 8.03 \\
\hline 4 & Thailand & 3182811 & 17.26 & 1951.50 & 44.63 & 7.47 \\
\hline 5 & Singapore & 2669359 & -10.50 & 1882.84 & -9.60 & 7.20 \\
\hline 6 & Bangladesh & 5230787 & -20.38 & 903.57 & -24.25 & 3.46 \\
\hline 7 & Saudi Arabia & 4865678 & 21.29 & 873.26 & 16.58 & 3.34 \\
\hline 8 & Pakistan & 4811003 & 33.34 & 815.76 & 28.66 & 3.12 \\
\hline 9 & United Arab Emirates & 3501082 & 25.36 & 618.60 & 23.85 & 2.37 \\
\hline 10 & Iran & 3141700 & 25.13 & 527.66 & -36.56 & 2.02 \\
\hline 11 & Indonesia & 617503 & -24.15 & 316.02 & -25.10 & 1.21 \\
\hline 12 & Iraq & 1397076 & 273.05 & 234.55 & 235.04 & 0.90 \\
\hline 13 & Poland & 606913 & 72.90 & 227.37 & 22.83 & 0.87 \\
\hline 14 & Egypt & 1344956 & 73.15 & 224.99 & 57.62 & 0.86 \\
\hline 15 & Turkey & 894220 & 126.26 & 153.68 & 1.47 & 0.59 \\
\hline 16 & Czech & 177664 & -44.69 & 129.59 & -48.02 & 0.50 \\
\hline 17 & Kuwait & 564637 & 0.49 & 123.64 & -8.93 & 0.47 \\
\hline 18 & Israel & 488460 & 15.98 & 119.69 & 1.09 & 0.46 \\
\hline 19 & Jordan & 692745 & -10.52 & 116.74 & -17.53 & 0.45 \\
\hline 20 & Lebanese & 536321 & 22.18 & 102.58 & 22.97 & 0.39 \\
\hline
\end{tabular}


2) Guangxi province has become the fastest growing province in China's "Belt and Road" export value

From January to November 2017, there were 1,672 Chinese exporters of Chinese medicine "Belt and Road", an increase of 52 over the same period of last year. The number of its Chinese business enterprises was 130, with an export value of 140 million U.S. dollars, an increase of $100.74 \%$ year-on-year. Its export volume accounted for $18.35 \%$ of China's "Belt and Road" export value, and 1,385 private enterprises. From January to November 2017, the export value of privately-owned Chinese medicine "Belt and Road" private enterprises was 488 million US dollars, a year-on-year increase of $6.21 \%$, accounting for $64.17 \%$. There were 78 foreign-owned enterprises with an export value of 47.764 million US dollars, a year-on-year decrease of $25.85 \%$, accounting for $6.28 \%$. There are 45 Sino-foreign joint ventures with an export value of 78.0054 million U.S. dollars, a year-on-year decrease of $0.06 \%$, accounting for $10.25 \%$. Among them, the export amount of Chinese medicine companies in each region and the number of export companies are shown in Table III [5].

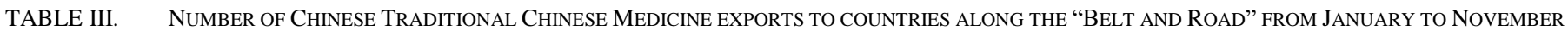
2017 (UNIT: 10,000 US DOLLARS, \%)

\begin{tabular}{|c|c|c|c|c|c|}
\hline No. & Area & $\begin{array}{l}\text { Export } \\
\text { amount }\end{array}$ & $\begin{array}{l}\text { The export } \\
\text { amount is the } \\
\text { same as the } \\
\text { previous year }\end{array}$ & $\begin{array}{c}\text { The } \\
\text { proportion } \\
\text { of export } \\
\text { amount }\end{array}$ & $\begin{array}{c}\text { Number of } \\
\text { export } \\
\text { companies }\end{array}$ \\
\hline total & China & 76069.78 & 12.05 & 100 & 1672 \\
\hline 1 & Guangxi & 10974.67 & 330.77 & 14.43 & 46 \\
\hline 2 & Guangdong & 9866.77 & -0.20 & 12.97 & 178 \\
\hline 3 & Anhui & 9344.62 & 24.07 & 12.28 & 65 \\
\hline 4 & Jiangxi & 5716.22 & -21.45 & 7.51 & 56 \\
\hline 5 & Yunnan & 5273.13 & 4.21 & 6.93 & 46 \\
\hline 6 & Sichuan & 4314.02 & 17.45 & 5.67 & 51 \\
\hline 7 & Jiangsu & 3670.57 & -7.37 & 4.82 & 138 \\
\hline 8 & Hunan & 3285.76 & -4.07 & 4.32 & 78 \\
\hline 9 & Zhejiang & 3275.76 & 8.54 & 4.31 & 223 \\
\hline 10 & Hebei & 3270.07 & 3.05 & 4.30 & 43 \\
\hline 11 & Shandong & 3058.05 & -8.54 & 4.02 & 143 \\
\hline 12 & Fujian & 2891.36 & 3.53 & 3.80 & 51 \\
\hline 13 & Beijing & 1898.76 & 26.55 & 2.50 & 48 \\
\hline 14 & Shanghai & 1456.91 & -30.15 & 1.91 & 116 \\
\hline 15 & Shanxi & 1304.07 & 59.96 & 1.71 & 115 \\
\hline
\end{tabular}

the continuous optimization of the domestic resources allocation of medicinal materials, the transformation and upgrading of the traditional medicinal materials market, the implementation of the national "One Belt and One Road" policy is ongoing, and many countries in the "One Belt and One Road" are potential markets for Chinese medicine exports. Therefore, China's Chinese herbal medicines and decoction pieces give birth to greater opportunities for export to countries and regions of the Belt and Road Initiative. With the "Belt and Road" strategy and the implementation of the strategy of "promoting Chinese medicine to the world" proposed by General Secretary Xi, It can be said that Chinese medicine companies have shown a good development trend toward the world, and China's Chinese medicine industry has great potential for development in the international market. China and the "Belt and Road" countries and regions are on the path of rapid development.

\section{BARRIERS TO CHINA'S TCM EXPORTS}

Promoting Chinese medicine to the world in the construction of the "One Belt and One Road" is not only an economical trade but also a cultural dissemination. It plays an important role in promoting China's economic development, enhancing international cultural influence and identity, and jointly safeguarding human health. However, at present, China's TCM is still in its infancy in the world, and it still faces problems such as huge differences in Chinese and Western cultures, unstandardized standards, many barriers to service trade in TCM, and lack of intellectual property rights and talents.

\section{A. Cultural Trade Barriers}

Due to the differences in the historical and cultural backgrounds of the East and the West, differences in principles and thinking methods between Western medicine theories and TCM theories have created barriers to cultural 
trade in TCM exports. The development of Chinese medicine in countries along the "Belt and Road" is uneven, and there is a big difference in the degree of national legislation and public recognition. In general, Chinese medicine has a high degree of recognition in Southeast Asia, and it has generally been recognized by the government and the public in East Asia and South Asia. There is a general lack of legislation and management of Chinese medicine in Central Asia, West Asia, and Africa. There is a huge difference between European and American countries' culture and Chinese culture, and there is a strong resistance to Chinese medicine. There are many restrictive laws and regulations in European and American countries. Therefore, Chinese medicine exports to Central and Eastern Europe are very limited and market share is very low. There are differences between Chinese and Western cultures, and it is difficult for Chinese medicine to be recognized by more countries.

\section{B. Technical Barriers to Trade}

Technical barriers to trade have become the main barriers to restricting the export of Chinese medicines. Many countries and regions along the "Belt and Road" initiative have set up technical trade barriers to raise standards for access to the Chinese medicine market and restrict Chinese medicine exports. The technical trade barriers encountered in Chinese medicine exports mainly include:

\section{1) Standardization barrier}

The countries along the "One Belt and One Road" are still lacking unified international standards and norms related to Chinese medicine. At present, although more than 90 countries, including countries along the "One Belt and One Road," have formulated registration standards for botanicals, they are generally formulated with reference to Western medicine standards. Practice has proved that the standards of quality control, production technology and product registration of Chinese medicine cannot completely imitate modern western medicine and botanical medicine. The standard specifications that have the characteristics of TCM business and are generally recognized by the national society have not yet been established, which hinders the international exchange and cooperation development of TCM. Therefore, the standardization issue has great restrictions on the export of Chinese medicine.

\section{2) Intellectual property barriers}

The importance of Chinese medicine to intellectual property rights is very low, so the intellectual property barriers encountered in the international market are very serious. On the one hand, traditional Chinese medicine companies lack knowledge of intellectual property rights and their emphasis on intellectual property rights is insufficient. Chinese patent medicines generally do not receive corresponding protection of intellectual property rights, and when they are infringed by intellectual property rights, they cannot justify applying for protection. On the other hand, traditional Chinese medicine without intellectual property rights is difficult to establish on the international market, but the process of foreign countries applying for certification of intellectual property rights for Chinese medicine is very complicated. For a class of Chinese medicines to obtain the final certification, not only strict compliance with the certification standards, but also need to spend a lot of money and time. Therefore, intellectual property barriers also have great restrictions on the export of Chinese medicines.

\section{3) Barriers to packaging and labelling}

The main function of the package is to protect and explain the product. There are strict regulations on the packaging of natural medicines in the international market. This is also because medicine is an important field involving personal safety. However, the packaging of Chinese traditional Chinese medicine export products has always been relatively crude, and the labels are also largely inconsistent with regulations. The product descriptions are not standardized. Therefore, they often encounter obstacles in this area [6].

\section{CHINA'S TCM PHARMACEUTICAL EXPORT COUNTERMEASURES}

In order to reduce the impact of barriers encountered in the export of Chinese medicine to China's traditional Chinese medicine companies and industries, China should look for changes that suit its national conditions in light of changes in the current international situation. This article mainly from the enterprise, industry and national level to deal with China's traditional Chinese medicine barriers encountered.

\section{A. Government-level Countermeasures}

1) Strengthen the publicity of Chinese medicine culture and break through cultural barriers

Chinese medicine is an important part of the extensive and profound Chinese culture. To a large extent, one of the reasons why the international community does not recognize or accept Chinese medicine is that it does not understand or recognize Chinese culture. In recent years, China's economic strength has become stronger and stronger, and the improvement of its overall national strength has enabled China's position in the international market to continue to increase. The radiation scope of China's economy has expanded and the scope of radiation of Chinese culture has also expanded. China should seize this opportunity. In order to increase the propaganda of Chinese medicine culture, so that more people accept the culture of Chinese medicine, break through the cultural barriers encountered in the export of Chinese medicine.

2) Strengthen trade negotiations and eliminate technical barriers to trade

Technical barriers to trade are the main barriers to China's exports of traditional Chinese medicines. Various countries have adopted laws and regulations to set up different standards for technical trade barriers, so that Chinese medicines cannot appear in the international market in the form of pharmaceuticals, and they simply cannot open up the international pharmaceutical market. Under such circumstances, it is necessary for the government to strengthen bilateral or multilateral trade negotiations with other countries, negotiate specific technical trade barriers set up by different countries, and create channels for Chinese medicine exports. After the outbreak of the financial crisis, compared to other countries, the impact on China's economy is relatively small. China is even seen as an important force capable of saving the 
international economy. Many countries hope to recover the economy with the help of China. China can take this opportunity to negotiate the entry standards for Chinese medicine in the international market, sign agreements on reducing technical barriers to trade, reduce the barriers for Chinese medicines to enter the international market, and eliminate technical barriers to trade.

3) The government formulates relevant policies and regulations and formulates standards that meet the international market requirements for Chinese medicines

One of the biggest problems encountered in the export of Chinese medicine is the standardization of Chinese herbal medicines, and the second is the problem of over-standard and pesticide residues in traditionuseal Chinese medicines. However, these problems often arise beca the country lacks corresponding policies, laws and regulations to regulate the production of traditional Chinese medicines, and there is also a lack of corresponding supervision mechanisms. In the production process, Chinese traditional medicine production enterprises pursue high profits in the immediate future, extensive operations, and excessive heavy metals in Chinese herbal medicines. As well as a large amount of pesticide residues, it does not meet international standards. Therefore, the government must formulate special laws and regulations on production and sales of traditional Chinese medicine, establish and improve the quality control system for traditional Chinese medicines, establish a supervision and security system, and strictly supervise and control the production and export of traditional Chinese medicines.

4) Emphasizing the protection of intellectual property rights, the government has stepped up the guidance of Chinese medicine companies

Chinese medicine is an original ethnic medicine industry in China. However, awareness of intellectual property rights in traditional Chinese medicine companies is very weak. Chinese patent medicines generally do not receive corresponding intellectual property protection. The reason is that foreign countries are very complex in applying for certification procedures for Chinese medicines. For a class of Chinese medicines to receive the final certification, it not only needs to strictly comply with the complex certification standards, but also requires a lot of money and time. This led to the reluctance of most Chinese medicine companies to conduct intellectual property certification procedures, but the international market for Chinese medicine without intellectual property rights was unacceptable, and corresponding intellectual property protection was not obtained. Therefore, Chinese medicine companies should attach importance to the importance of intellectual property rights and actively apply for corresponding protection of intellectual property rights. In this process, the government should guide it, provide assistance in funding and application channels, and strengthen communication with the government of the target market countries.

\section{B. Enterprise-level Countermeasures}

\section{1) Traditional Chinese Medicine Enterprises Should} Accelerate System Reform

China's TCM companies are mostly small in scale, lagging behind in management methods, and lacking technical capabilities, capital capabilities, and management capabilities. Small businesses often lack the resources they need to develop international markets. When entering the European, American, and international markets, they do not see long-term benefits. They have serious short-term views and often cannot open up the international market. The backward enterprise system will also be fatally hit when many well-known foreign pharmaceutical companies invade the Chinese market. Therefore, the first thing to do is to change the corporate system, learn from the successful experience of domestic and foreign outstanding companies, and change the unreasonable part of the existing enterprise system.

2) Increase research investment and enhance independent innovation capabilities

Traditional Chinese medicine companies need to increase their investment in the research of traditional Chinese medicines. At this stage, the exports of proprietary Chinese medicines are very few, and there is even a deficit. In order to promote the export of Chinese medicine, it is mainly to increase the export of proprietary Chinese medicines and increase the market share of proprietary Chinese medicines in the international pharmaceutical market. Therefore, increase the investment in traditional Chinese medicine research, enhance the independent innovation ability of traditional Chinese medicine companies, cultivate the core competitiveness of traditional Chinese medicine, and modernize traditional Chinese medicine. Only in this way can we achieve real advantages in international competition and increase the share of traditional Chinese medicines in the international market.

\section{3) Actively cultivate Chinese medicine talents}

Traditional Chinese old traditional Chinese medicine has exquisite techniques and rich experience. It has been highly praised for a long time. With the increase in the importance attached to traditional Chinese medicine by the country, and the increasingly prominent side effects of Western medicine, and the increasing acceptance of Chinese medicine by people both at home and abroad, the talents of traditional Chinese medicine are very inadequate. Therefore, we must increase the training of talents in Chinese medicine. In the cultivation of TCM talents, special attention should be given to the integration of TCM talent cultivation methods with the practice of TCM. Talent cultivation of TCM practitioners must capture successful methods in the cultivation of TCM personnel, but it must also combine the actual needs of TCM talents. Pay attention to their clinical ability and the cultivation of Chinese medicine knowledge reserve ability [7].

\section{CONCLUSIONS}

This article elaborates on the status quo of Chinese medicine exports, analyzes the barriers China's Chinese medicine has encountered in exporting countries and regions along the Belt and Road, and puts forward rational proposals 
for responding to the export of Chinese medicine. However, this article also has some defects.

The main conclusions of this paper are as follows: First, China's Chinese medicine exports have continued to grow steadily, and Chinese medicine has developed rapidly, but its share in the international market is only $5 \%$, and its market share is low. Secondly, from the perspective of product export structure, China's export products are mainly low-value-added products such as Chinese herbal extracts, Chinese herbal medicines, and decoction pieces. The structure of this product does not match the identity of the originating country of Chinese medicine. Third, the barriers to exports of Chinese medicine are mainly composed of: cultural trade barriers and technical trade barriers. Among them, the technical barriers to trade are the main barriers to China's exports of traditional Chinese medicine. Fourth, the barriers to the export of Chinese medicine in China will cause the public to misunderstand, distrust, or not recognize traditional Chinese medicine. The practice of prejudice and discrimination against China in all countries affects the market access of Chinese medicine products and affects the competitiveness of Chinese medicine products. Therefore, this article put forward corresponding suggestions from the government and enterprise level.

\section{ACKNOWLEDGMENT}

Funding for this research was provided by National Natural Science Foundation of China under grants 71663058 and
71662016. This article was completed under the careful guidance and careful teaching of Duan Yunlong's teacher. From the selection of the topic, the method of argumentation, and the collection of basic materials, all of them devoted to the teacher's efforts and sweat. Hereby express my sincere thanks!

\section{REFERENCES}

[1] Dahlia Patricia Sterling. "A New Era in Cultural Diplomacy: Promoting the Image of China's "Belt and Road" Initiative in Asia," Open Journal of Social Sciences, vol. 06, pp. 102-116, 2018.

[2] Huang Ping, and Ma Aixia. "Analysis of Technical Barriers to Trade in Traditional Chinese Medicine Exports," International Medicine \& Health Guidance News. vol. 19, pp. 62-64, 2005.

[3] Li Yinjie. "An Analysis of the Barriers and Countermeasures Faced by China's Traditional Chinese Medicine Export," Times Finance. vol. 12, pp. 193-200, 2014.

[4] Ma Junchi. "The Challenge of Different Perceptions on the Belt and Road Initiative," Croatian International Relations Review, vol. 23, pp. 149-168, 2017.

[5] Wen Zhanquan. "Chinese government's coping strategies for international marketing of green trade barriers," Chinese Medicine Management, vol. 07, pp. 1841-1843, 2007.

[6] Xiaodong Zhang, and Yiyi Sun. "Analysis of China's Export of Traditional Chinese Medicines and Trade Barriers," Foreign Economic Trade Practice. vol. 03, pp. 14-17, 2011.

[7] Yue Gao. "Influences of Institutional Differences on Chinese Enterprises' Investment on Countries in 'The Belt and Road'Strategy_-Based on Regulatory Effects of Ethnic Chinese in Host Countries," Modern Economy, vol. 08, pp. 551-566, 2017. 